\title{
Modeling of Thermal and Optical Processes in Translucent Structures Filled with PCM Layer Using Moving Mushy Volume Approach
}

\author{
Tomasz Kułakowski ${ }^{1}$, Dariusz Heim ${ }^{2}$ \\ ${ }^{1}$ Warsaw University of Technology, Warsaw, Poland \\ ${ }^{2}$ Lodz University of Technology, Lodz, Poland
}

\begin{abstract}
The paper deals with the development of the new numerical model of heat transfer with latent heat storage including short wave radiation. The model is based on original, moving mushy volume approach which is described in details taking into account more realistic description of phase change transition of PCM layer. The main advantages of presented method is the determination of solar radiation distribution within the structure and taking into account the intermittent properties of mushy state of PCM. The model was adopted to analyse heat transfer in complex triple glass component with one cavity filled with PCM. The initial simulation results presents the temperature distribution as well as latent heat storage. The results were presented for characteristic days in a year.
\end{abstract}

\section{Introduction}

The application of phase change materials in different building elements, from opaque to transparent, become more and more popular. Pure phase change materials (PCM) closed in the transparent structure like glazing unit, glass container or polycarbonate panels are also penetrable for short wave radiation (Silva, Vicente, and Rodrigues 2016). In solid and mushy state they are highly diffusive while in the liquid state they are completely translucent. When material is liquid its transmittance is very high (Bianco et al. 2018), while in solid and mushy state exponentially decreases versus thickness of the layer. There are some papers treating about the physical parameters of structures with PCM in mushy states, e.g. thermal conductivity (Wang et al. 2016), but for dynamic simulations of heat transfer involving the solar radiation distribution the whole new approach of modelling mushy state is still necessary. The existing models do not consider dynamic changes of absorptance/transmittance of PCM during phase change, which is highly important for the radiation absorption.

The general aim of this research was to develop the new numerical model of heat transfer including short wave radiation. This method is based on original, moving boundary mushy volume approach which is described in details taking into account more realistic description of phase change transition of PCM layer in triple glazed unit. The existing solution methods assumed that PCM layer melted homogenously in the whole layer (Goia, Perino, and Serra 2014). In fact the PCM layer first become whole mushy and then split into a liquid and mushy phases till the moment when the whole volume become fully melted. The original methodology includes the changeable absorptivity-transmissivity of the mushy layer as well as location of this layer in the whole component. The presented methodology can be implemented in any building performance simulation environment using control volume or finite difference method.

\section{Modelling of PCM - a review}

Heat transfer within the phase change has been a subject of numerous researches since $19^{\text {th }}$ century - firstly formulated by Lame and Clapeyron (1831) and further developed by Joseph Stefan (1890). Nowadays, it is called Stefan problem and its solution is strictly connected to tracking front of melting or solidifying (Front Tracking Method or Moving Boundary Condition). First considerations treated mostly about phase change taking place in freezing/melting of water (Alexiades and Solomon 1993). Later problem was explored in various fields, e.g. solidifying of metal casts, cooling of electronics (Weng et al. 2011), etc. In building physics heat transfer through PCM materials has been subject of numerous publications in different applications like opaque elements: brickwork structures (Vicente and Silva 2014) \& (Wang et al. 2016), mortars (Olivieri et al. 2018) \& (Rao, Parameshwaran, and Ram 2018) as well as plasters (Heim and Wieprzkowicz 2016) \& (Lachheb et al. 2017). The second type of building components in the area of interest are translucent structures filled with PCM materials - double glazed vertical windows (Goia, Perino, and Haase 2012), (Liu et al. 2018), (Li et al. 2014) and double glazed skylights filled with PCM (Liu et al. 2017). In listed papers authors presented different approaches to existing modeling method - (Goia, Perino, and Haase 2012) used simple energy balancing method in analogy to electrical circuits; $\mathrm{Li}$ in ( $\mathrm{Li}$ et al. 2014) used Finite Difference Method; Liu in (Liu et al. 2018) and (Liu et al. 2017) used Finite Volume Method (or Control Volume Method). The novel approach presented in this paper is closest to the model presented by Liu in (Liu et al. 2018) and (Liu et al. 2017) where mushy state was included. Moreover, the absorption of solar radiation was dependent from thickness of solid and liquid layers of PCM. The main differences is the method applied to solve solar radiation distribution within the structure. Liu 
used ray tracing method while in this study authors used net balancing method. The case considered here is also more complex and the triple glazed window with one gap filled with PCM and one filled with gas is proposed as a case study. The third and the most important difference is taking into account the intermittent properties of so called mushy state of PCM.

\section{Proposed numerical model}

Depending on chosen method of solving heat transfer phenomenon analysis needs different mathematical formulation of the problem. In presented paper authors used Control Volume Method (or Finite Volume Method) which bases on integral formulation of extensive quantity conservation law:

$$
\frac{\delta}{\delta \tau} \int_{\Omega_{p}} \varphi d \Omega-\oint_{\Gamma_{p}}\left(\lambda \frac{\delta \varphi}{\delta x_{j}}\right) n_{j} d \Gamma=\int_{\Omega_{p}} Q_{V} d \Omega
$$

$\varphi \quad$ - specific enthalpy $[\mathrm{J} / \mathrm{kg}]$

$\tau \quad$ - time $[\mathrm{s}]$

$\lambda$ - heat conduction coefficient $[\mathrm{W} /(\mathrm{m} \cdot \mathrm{K})]$

$Q \quad$ - internal heat source $\left[\mathrm{W} / \mathrm{m}^{3}\right]$

$\Omega_{p} \quad$ - analysed region

$\Gamma_{p} \quad$ - edge of region

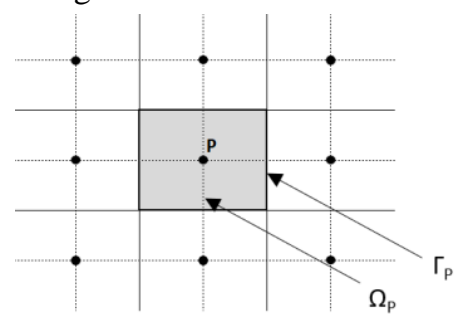

Figure 1. Exemplary scheme of Control Volume geometry discretization.

Differential equations were replaced with finite differences. Next step in solving problem was discretization of the domain (geometry). This paper describes one dimensional analysis of the heat transfer through the centre of the window. This assumption does not cover fluctuations of heat transfer caused by linear thermal bridges etc., but similar approach gave satisfying results in several researches (Liu et al. 2018). Authors decided that division will be done so that nodes of control volumes representing glass planes will be located on their surfaces. In nodes 1, 2, 4, 12 such approach helps in using convective boundary condition. In nodes 5 and 11 it gives temperature results on the surfaces that are in contact with PCM layer, which was important because no averaged heat conduction parameters had to be used between nodes $5-6$ and $10-11$.

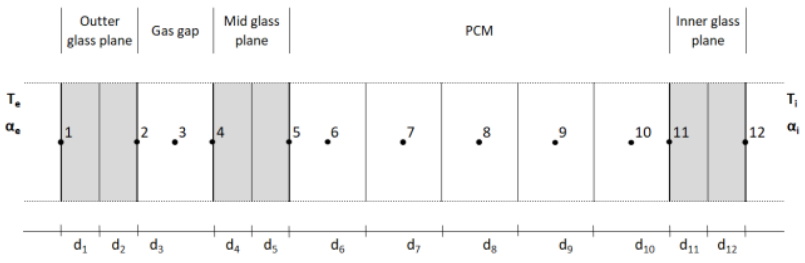

Figure 2. Control Volume geometry discretization.
Analysis of energy balance in presented structure demand some assumptions when it comes to thermal parameters of its components. As for glass planes specific heat capacity and thermal conductivity does not vary significantly in temperature ranges appearing in building structures and may be treated as constant values, for air gap and PCM layer some additional simplifications are needed.

Specifications of Phase Change Materials properties usually present values for liquid and solid states. In reality between these two states the additional one appears so called mushy state. It is intermediate form that has parameters of neither liquid nor solid state. Because model presented in this paper was developed to perform simulations for time period of one year, authors decided to include mushy state in calculations. It might be crucial in winter situations were low temperatures on the outside makes melting impossible, but solar radiation penetrating through PCM layer may cause softening of inner parts without melting. In authors opinion including mushy state is important because its optical properties are far from liquid and cause higher absorptance. In order to do so authors used $\beta$ parameter introduced by Liu in (Liu et al. 2018) and (Liu et al. 2017). If $T_{S}$ is the highest temperature that solid state can reach and $T_{L}$ is lowest temperature of liquid then for actual temperature $T$ :

$$
\begin{array}{ll}
\text { for } T<T_{S} & \beta=0 \\
\text { for } T_{S}<T<T_{L} & \beta=\frac{T-T_{S}}{T_{L}-T_{S}} \\
\text { for } T>T_{L} & \beta=1
\end{array}
$$

Knowing $\beta$ coefficient calculations of enthalpy $(H)$, extinction coefficient $(K)$ and refractive index $(n)$ were performed according to following equation:

$$
X(\beta)=X_{S}+\beta \cdot\left(X_{L}-X_{S}\right)
$$

$X \quad$ - analysed parameter $(H, K$ or $n)$

$X_{S}$ - value of parameter $X$ for solid state

$X_{L} \quad$ - value of parameter $X$ for liquid state

Calculations of enthalpy of PCM is one of the most demanding steps in transient heat transfer problems because it is strictly connected to the temperature of analysed volume, while temperature is unknown. Precision in this matter is very important while latent heat phenomenon is the crucial part of presented research. Such coupling requires introduction of algorithm, whether iterative or approximate (Al-Saadi and Zhai 2013). In presented paper authors decided to use iterative calculations basing on linearization of enthalpy function within several ranges to make it applicable to Tri Diagonal Matrix Algorithm (TDMA).

Approach described in equation 1 is sufficient for solving conduction problem involving heat gains from solar radiation calculated independently. Heat transfer through air gap requires some additional calculations considering convection and radiation within the air gap, resulting with equivalent heat conduction coefficient that could be applied to equation 1 . 
Convection heat transfer was solved with formulas basing on similarity theory giving equivalent heat conduction coefficient:

$$
\lambda_{r}=\varepsilon_{k} \cdot \lambda_{f}
$$

where

$\lambda_{r}$ - equivalent heat conduction coefficient $[\mathrm{W} /(\mathrm{m} \cdot \mathrm{K})]$

$\varepsilon_{k} \quad$ - transfer intensity coefficient

$\lambda_{f} \quad$ - gas heat conduction coefficient for temperature $T_{f}$ $[\mathrm{W} /(\mathrm{m} \cdot \mathrm{K})]$

$$
T_{f}=0,5 \cdot\left(T_{1}+T_{2}\right)
$$

where $T_{1}$ and $T_{2}$ are temperatures of opposite surfaces of the gap.

Transfer intensity coefficient is calculated from following equation:

$$
\varepsilon_{k}=0,18 \cdot\left(G r_{f} \cdot P r_{f}\right)^{0,25}
$$

where

$G r_{f}$ - Grashof number calculated for $T_{f}$

$P r_{f}$ - Prandtl number for $T_{f}$

Knowing the air gap depth $\delta$ we can calculate equivalent heat conduction resistance connected to convection within the gap from the following equation:

$$
R_{c}=\frac{\delta}{\lambda_{r}}
$$

Radiation heat flux is given by Stefan-Boltzmann law:

$$
q_{\text {rad }}=\varepsilon_{c} \cdot C \cdot\left(\frac{T_{1}^{4}}{100}-\frac{T_{2}^{4}}{100}\right)
$$

where:

$$
\begin{array}{ll}
\varepsilon_{c} & \text { - equivalent emissivity for parallel surfaces } \\
C & \text { - radiation constant }
\end{array}
$$

Temperatures $T_{1}$ and $T_{2}$ in equation (8) are given in [K].

Knowing heat flux we can calculate equivalent heat conduction resistance connected to radiation within the gap from following equation:

$$
R_{r}=\frac{q_{\text {rad }}}{\left(T_{1}-T_{2}\right)}
$$

Heat transfer resistance of air gap including convection and radiation heat transfer is calculated as follows:

$$
R_{\text {gap }}=\frac{1}{\frac{1}{R_{C}}+\frac{1}{R_{r}}}
$$

Equivalent heat conduction coefficient is given by following equation:

$$
\lambda_{\text {gap }}=\frac{\delta}{R_{\text {gap }}}
$$

Applying this parameter to equation 1 allows to perform calculations without including advanced computational fluid dynamics techniques. Most of presented equations require temperatures in nodes representing gap surfaces in current time step while being necessary to calculate those. Such coupling need introduction of iterative algorithm or use some assumption. In the presented method authors used iterative calculations.
During the heat transfer analysis, calculations of absorption of solar and diffuse radiation are performed. Most commonly used method is ray tracing method. It has several advantages, e.g. in typical structures where no change of optical parameters and geometry is considered once calculated solution is possible to be applied in each time step. In case described in this paper, when change of optical parameters occur this method need as many solutions as may appear. E.g. when melting of PCM is starting from the outer side right after situation where whole PCM layer is solid, mushy volume appears in contact with outer side, as melting proceeds liquid layer is replacing mushy volume which is moving to the inner surface. Then there is only liquid and mushy, and the last step is only liquid. Melting from the outside needs 5 different solution of radiation distribution, but there is also possible melting from the inside, and melting from both sides. This makes Ray Tracing Method difficult to be applied in further simulation of translucent structures with PCM. Therefore, in this study authors decided to use Net Radiation Balancing Method which was introduced by Hottel and widely described in (Robert Siegel 1999). It is more demanding in computational proceeding but does not limit solutions to predefined cases. This method bases on formulation of number of equations sufficient to solve radiation distribution in structure by balancing it on chosen surfaces. Authors decided to choose as many surfaces as there are in division of Finite Control Volumes, which makes it much easier to introduce radiation absorption results to heat transfer calculation model.

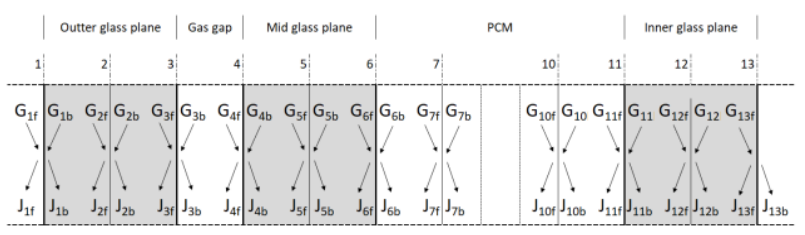

Figure 3. Net Radiation Balancing Method application.

In presented model $G_{l f}$ is analysed solar radiation, whether direct or diffuse. Idea of radiation net balancing is presented on the example of layer 3 - all of the components are unknown and because of difference in refractive indexes between adjacent layers reflection occurs:

$$
\begin{gathered}
G_{3 f}=J_{2 b} \cdot\left(1-\tau_{2.3}\right) \\
J_{3 f}=G_{3 f} \cdot\left(\rho_{3 f}\right)+G_{3 b} \cdot\left(1-\rho_{3 b}\right) \\
G_{3 b}=J_{4 f} \cdot\left(1-\tau_{3.4}\right) \\
J_{3 b}=G_{3 b} \cdot\left(\rho_{3 b}\right)+G_{3 f} \cdot\left(1-\rho_{3 f}\right)
\end{gathered}
$$

Proper order of equations creates 5-diagonal matrix which allows using modified Thomas algorithm. In each time step matrix operations are computed to bring result of absorbed radiation separately for solar and diffuse components. Amount of energy absorbed in each layer is calculated as follows (example of energy absorbed between surfaces 2 and 3 ). 


$$
A_{23}=\left(J_{3 f}+J_{2 b}\right) \cdot\left(1-\tau_{2.3}\right)
$$

Especially in case of solar radiation, optical properties are different for each angle of incidence. This is why authors decided that since presented tool is supposed to perform complex analysis of energy balance in simulations for one year, exact properties should be included.

Angle of incidence for each hour was calculated in compliance with methodology presented in (Duffie and Beckman 2001).

$$
\cos (\theta)=\sin (\delta) \cdot \sin (\varphi) \cdot \cos (\beta)-\sin (\delta) \cdot
$$

$\cos (\varphi) \cdot \sin (\beta) \cdot \cos (\gamma)+\cos (\delta) \cdot \cos (\varphi) \cdot \cos (\beta) \cdot$

$\cos (\omega)+\sin (\delta) \cdot \sin (\varphi) \cdot \sin (\beta) \cdot \cos (\gamma) \cdot$

$\cos (\omega)+\cos (\delta) \cdot \sin (\beta) \cdot \sin (\gamma) \cdot \sin (\omega)$

$\theta \quad$ - angle of incidence [rad]

$\delta \quad$ - declination [rad]

$\varphi \quad$ - latitude[rad]

$\beta \quad$ - inclination of analysed surface [rad]

$\gamma \quad$ - azimuth [rad]

$\Omega$ - hour angle [rad], calculated according to (Duffie and Beckman 2001)

It is harder to calculate angle dependent optical parameters for diffuse radiation, which has no obvious directional characteristics. In weather data used in analysis only sum of radiation from sky and ground was given, which demanded some simplifications in calculations. Effective angle approach described in (Duffie and Beckman 2001) was fully sufficient for presented model. For vertical surfaces (as analysed) effective angle of incidence for diffuse radiation from ground and sky was about $60^{\circ}$ and optical parameters were calculated using that value.

Reflectivity was calculated from following relations:

$$
\text { for } \theta_{i}=90^{\circ} \text { and for } \theta_{i}=0^{\circ} \quad \rho_{f . i}=1
$$

$\rho_{f . i}=\left(\frac{n_{i-1}-n_{i}}{n_{i-1}+n_{i}}\right)^{2}$

$$
\text { for } \theta_{i} \neq 0^{\circ} \text { and } \theta_{i} \neq 90^{\circ}
$$

$$
\begin{aligned}
\rho_{f . i}=0,5 \cdot( & \left(\frac{\sin \left(\theta_{i-1}-\theta_{i}\right)}{\sin \left(\theta_{i-1}+\theta_{i}\right)}\right)^{2} \\
& \left.+\left(\frac{\tan \left(\theta_{i-1}-\theta_{i}\right)}{\tan \left(\theta_{i-1}+\theta_{i}\right)}\right)^{2}\right)
\end{aligned}
$$

Changes of angles of incidence caused by passing through boundary between two mediums (materials) was calculated according to Snell's law.

$$
n_{i} \cdot \sin \left(\theta_{i}\right)=n_{i+1} \cdot \sin \left(\theta_{i+1}\right)
$$

then:

$$
\theta_{i+1}=\arcsin \left(\frac{n_{i}}{n_{i+1}} \cdot \sin \left(\theta_{i}\right)\right)
$$

Notice that e.g. on surface 2 (Figure 3), which was introduced to model only to make easier application of absorption results to heat transfer model, the same refractive indexes of layers $1-2$ and $2-3$ cause no reflection.
Next parameter that is strongly angle dependent was transmittance. In presented model it was calculated according to Bouger's law.

$$
\begin{gathered}
\tau_{i . i+1}=e^{\left(-K_{i, i+1} \cdot l_{i . i+1}\right)} \\
l_{i . i+1}=\frac{d_{i . i+1}}{\cos \left(\theta_{i}\right)}
\end{gathered}
$$

$\tau_{i . i+1}$ - transmittance of layer between surfaces $i$ and $i+1$

$K_{i, i+1}$ - extinction coefficient of layer between surfaces $i$ and $i+1[1 / \mathrm{m}]$

$l_{i, i+1}$ - path of radiation between surfaces $i$ and $i+1$ [m]. To avoid singularity for angle of $90^{\circ} l$ was equal to $100 \mathrm{~m}$ (penalty method).

$d_{i . i+1}$ - thickness of layer between surfaces $i$ and $i+1$ $[1 / \mathrm{m}]$

$\theta_{i} \quad$ - angle of incidence on surface $i+1$ [rad]

\section{Model database and general assumption}

In this section the general assumptions for numerical calculation are provided. Simulation was performed for one year with time step of one hour and weather data for Warsaw (Typical Meteorological Year) as an example.

Simulation began with additional 48 hour period (startup hour) of warming up in purpose of avoiding artificial fluctuation at the beginning of the year. Internal temperatures were assumed to be constant during whole year and equal to $20^{\circ} \mathrm{C}$. Model is prepared to involve varying internal set-point, but authors decided that for purpose of this paper it will be more clear to omit melting caused by raise of internal temperatures.

Table 1. Material parameters used in calculations

\begin{tabular}{|c|c|c|c|c|c|}
\hline No. & Material & $\begin{array}{c}\text { Thickness } \\
\mathbf{d}[\mathbf{m}]\end{array}$ & $\begin{array}{c}\text { Specific } \\
\text { heat } \\
\mathbf{C}_{\mathbf{p}}[\mathbf{J} / \mathbf{k g K}]\end{array}$ & $\begin{array}{c}\text { Heat } \\
\text { conduction } \\
\text { coefficient } \\
\lambda[\mathbf{W} / \mathbf{m K}]\end{array}$ & $\begin{array}{c}\text { Density } \\
\boldsymbol{\rho}\left[\mathbf{k g} / \mathbf{m}^{3}\right]\end{array}$ \\
\hline 1 & Glass & 0.0020 & 840 & 0.800 & 180 \\
\hline 2 & Glass & 0.0020 & 840 & 0.800 & 180 \\
\hline 3 & Air gap & 0.0100 & 520 & 0.017 & 180 \\
\hline 4 & Glass & 0.0020 & 840 & 0.800 & 180 \\
\hline 5 & Glass & 0.0020 & 840 & 0.800 & 180 \\
\hline 6 & PCM & 0.0020 & $2000^{*}$ & 0.210 & 880 \\
\hline 7 & PCM & 0.0020 & $2000^{*}$ & 0.210 & 880 \\
\hline 8 & PCM & 0.0020 & $2000^{*}$ & 0.210 & 880 \\
\hline 9 & PCM & 0.0020 & $2000^{*}$ & 0.210 & 880 \\
\hline 10 & PCM & 0.0020 & $2000^{*}$ & 0.210 & 880 \\
\hline 11 & Glass & 0.0020 & 840 & 0.800 & 180 \\
\hline 12 & \multicolumn{6}{|c|}{ Glass } & \multicolumn{2}{|c|}{0.0020} & 840 & 0.800 & 180 \\
\hline
\end{tabular}

Parameters of specific heat given in Table 1 for PCM layers are not sufficient for complex analysis of transient heat transfer problem, and need some additional data given below. 
Table 2. Parameters of PCM - HC21

\begin{tabular}{|l|c|c|c|}
\hline \multicolumn{1}{|c|}{ Parameter } & Index & Unit & Value \\
\hline Specific heat & $c_{p}$ & {$[\mathrm{~J} / \mathrm{kgK}]$} & 2000 \\
\hline Latent heat & $Q_{L}$ & {$[\mathrm{~J} / \mathrm{kg}]$} & 155000 \\
\hline $\begin{array}{l}\text { Highest temperature of } \\
\text { solidus }\end{array}$ & $T_{S}$ & {$\left[{ }^{\circ} \mathrm{C}\right]$} & 18 \\
\hline $\begin{array}{l}\text { Lowest temperature of } \\
\text { liquidus }\end{array}$ & $T_{L}$ & {$\left[{ }^{\circ} \mathrm{C}\right]$} & 23 \\
\hline
\end{tabular}

Parallel to heat transfer calculations, solar radiation distribution within the structure is analysed. In this purpose optical parameters where defined as follows.

Table 3. Optical parameters of materials

\begin{tabular}{|l|c|c|}
\hline \multicolumn{1}{|c|}{ Index } & $\begin{array}{c}\text { Refractive index } \\
\boldsymbol{n}\end{array}$ & $\begin{array}{c}\text { Extinction } \\
\text { coefficient } \\
\boldsymbol{K}[\mathbf{1 / m}]\end{array}$ \\
\hline Air & 1.00 & 0 \\
\hline Glass & 1.50 & 32 \\
\hline Gas gap & 1.00 & 0 \\
\hline PCM solidus & 1.52 & 30 \\
\hline PCM liquidus & 1.43 & 5 \\
\hline
\end{tabular}

Transmissivity, reflectivity and absorptivity were calculated from relations explained in previous section using values presented above.

Authors decided to present results for three cases heating season $\left(16^{\text {th }}\right.$ January), cooling season $\left(6^{\text {th }}\right.$ July) and transitional season $\left(24^{\text {th }}\right.$ April). Examples were chosen to highlight importance of proper modelling of mushy volume. Results contain weather data (outside dry bulb temperature, direct and diffuse solar radiation), temperatures in nodes of CVM and stage of melting in PCM layers in each hour of the day. When it comes to stage of melting ( $\beta$ parameter) values higher than 0 and lower than 1 mean that it is mushy volume, 0 means solid, and 1 means liquid.

\section{Initial results}

\section{Heating season - results for $16^{\text {th }}$ January}

On $16^{\text {th }}$ January external dry bulb temperatures were varying from $-3.6^{\circ} \mathrm{C}$ to $4.1^{\circ} \mathrm{C}$ so with $T_{S}$ of $17.0^{\circ} \mathrm{C}$ melting caused only by thermal transmittance between internal and external environments was not expected (Figure 4). However, the direct solar radiation (it should be noticed how high it was compared to further data from the transitional and cooling seasons) absorption caused significant growth of the mushy volume. As a result during the period of peak gains, temperatures in the PCM layers were slightly higher than the internal environment temperature (compare results for 10:00, 11:00 and 12:00 to results for 8:00 and 14:00 on Figures 5 and 6) despite low outside air dry bulb temperatures.

Such results prove that profits of implementing PCM in the translucent structures can be important not only in the cooling or transitional seasons because of improving thermal comfort or reducing the energy consumption but also in the heating season significant benefits may be noticed.

That is very important information in case of rational applicability in climates similar to Polish where the heating season lasts about 220 days a year.

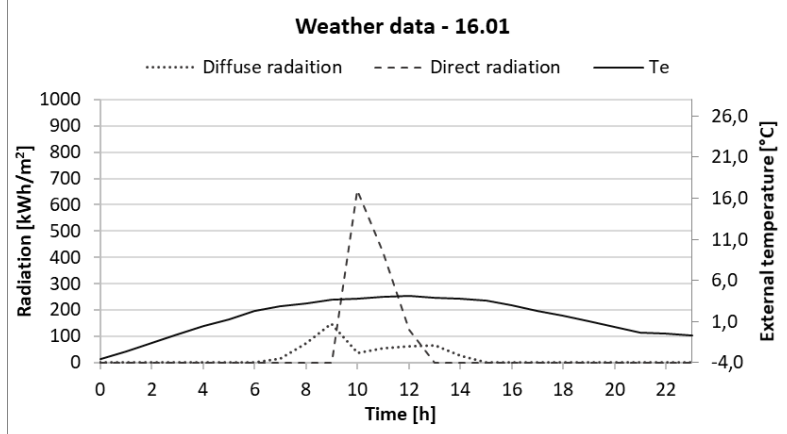

Figure 4. Weather data from typical meteorological year for $16^{\text {th }}$ of January.

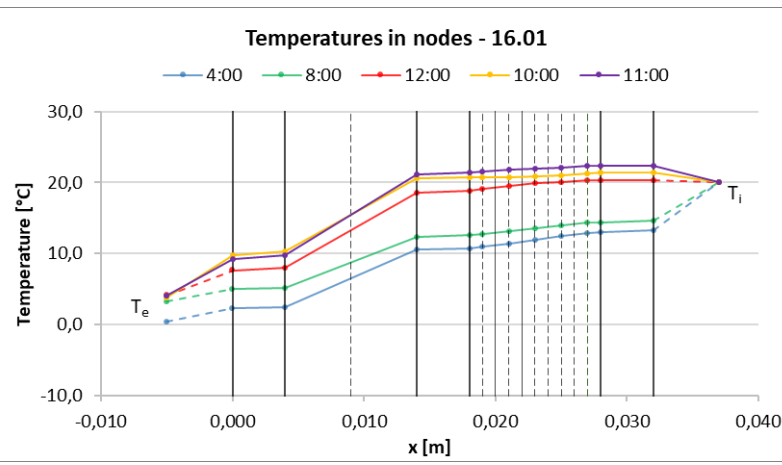

Figure 5. Temperatures in nodes of CVM model in exemplary hours before noon for $16^{\text {th }}$ of January.

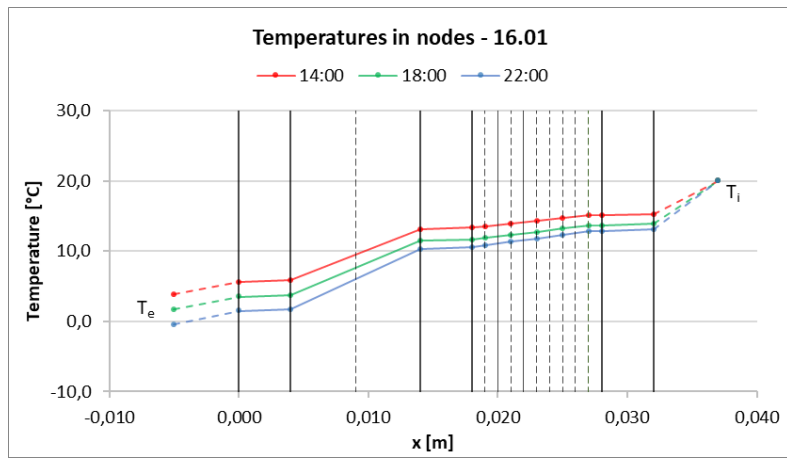

Figure 6. Temperatures in nodes of CVM model in exemplary hours after noon for $16^{\text {th }}$ of January. 


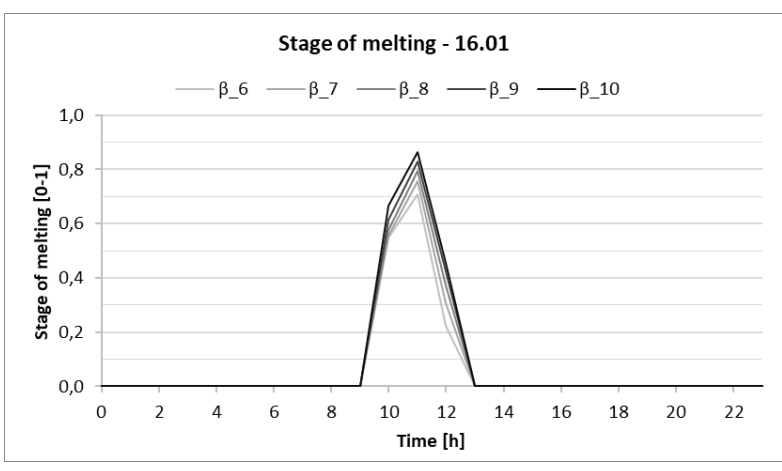

Figure 7. Stage of melting in layers 6-10 (nodes representing PCM layers) for each hour of the day $\left(16^{\text {th }}\right.$ of January).

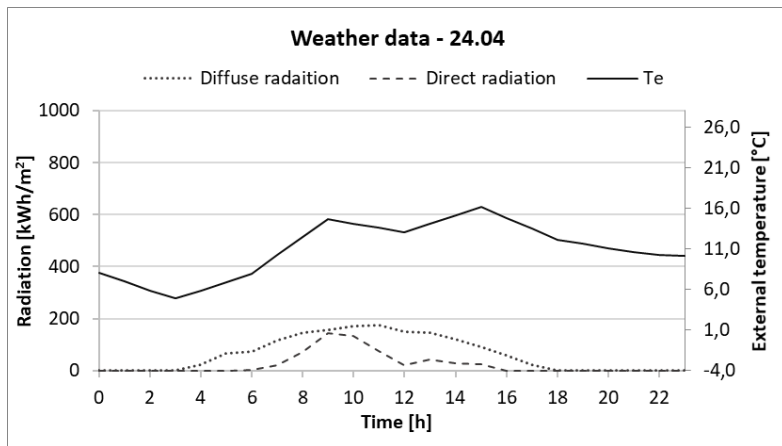

Figure 8. Weather data from typical meteorological year for $24^{\text {th }}$ of March.

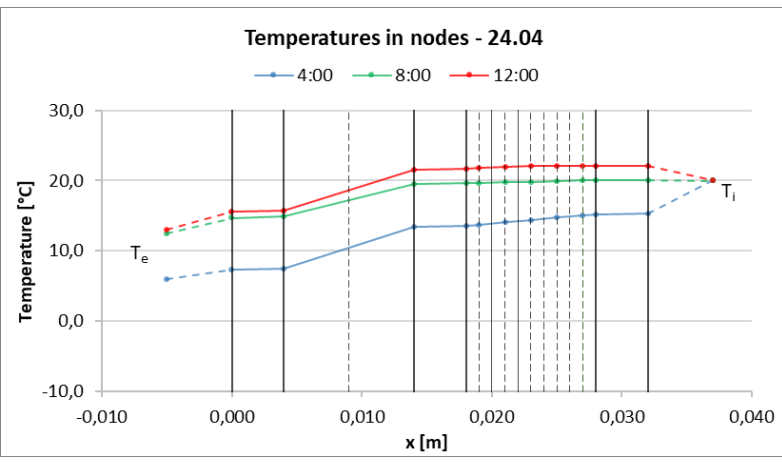

Figure 9. Temperatures in nodes of CVM model in exemplary hours before noon for $24^{\text {th }}$ of March.

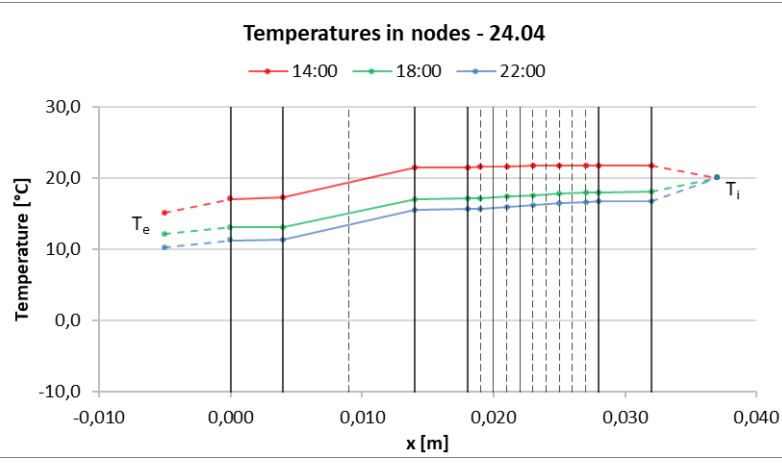

Figure 10. Temperatures in nodes of CVM model in exemplary hours after noon for $24^{\text {th }}$ of March.

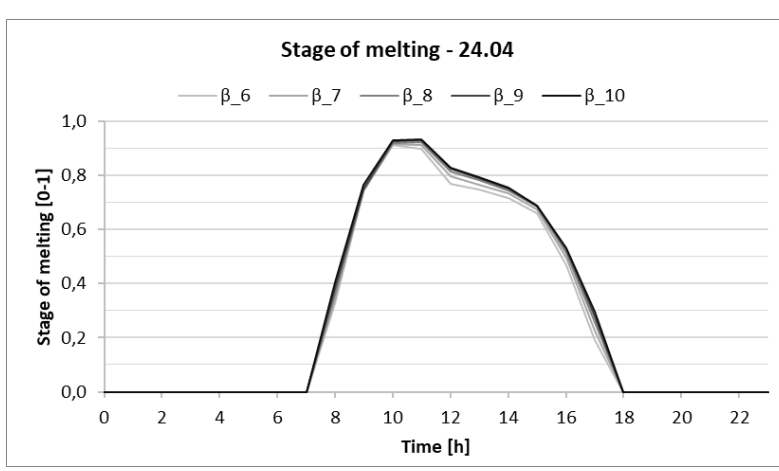

Figure 11. Stage of melting in layers 6-10 (nodes representing PCM layers) for each hour of the day $\left(24^{\text {th }}\right.$ of March).

\section{Transitional season - results for $\mathbf{2 4}^{\text {th }}$ April}

On $24^{\text {th }}$ March (Figure 8 ) external dry bulb temperatures were varying from $4.9^{\circ} \mathrm{C}$ to $16.2^{\circ} \mathrm{C}$ so with relatively high outside air dry bulb temperatures and $T_{S}$ of $17.0^{\circ} \mathrm{C}$ and $T_{i}$ of $20.0^{\circ} \mathrm{C}$ not only softening, but full melting was expected within the structure (at least in the innermost layers). However, such choice of the date for the exemplary results in the transitional season was done because of the relatively low direct solar radiation (lower than the diffuse during the whole day).

Analysing results on Figure 11 we can see that despite the relatively high outside air dry bulb temperatures full melting ( $\beta=1.0)$ did not happen in any of PCM Control Volumes. Comparison of figures presenting the stage of melting from the $16^{\text {th }}$ January (Figure 7 ) and $24^{\text {th }}$ March (Figure 11) shows that despite the full melting didn't take place time period of the softened PCM layer is much longer in the transitional season. This proves that even though radiation absorption is crucial for short term heat storage using PCM, in proper modelling of the heat transfer through translucent structures transmission cannot be omitted. It is mostly important during hours with no or with weak radiation.

This shows how important is yearlong simulation of the heat transfer through translucent structures filled with PCM in optimization of its parameters. Parallelly there is need for more detailed physical and optical parameters of PCM materials in mushy states.

\section{Cooling season - results for $4^{\text {th }}$ August}

On $4^{\text {th }}$ August (Figure 12) external dry bulb temperatures were changing from $17.8^{\circ} \mathrm{C}$ to $31.1^{\circ} \mathrm{C}$ so with $T_{S}=17.0^{\circ} \mathrm{C}$ (inside air temperature equal to $20^{\circ} \mathrm{C}$ ) melting is expected in all PCM layers. However in cooling season more interesting is behavior of PCM in night hours when solar radiation is not available whether it is fully solidifying or it stays mushy.

On the Figure 15 we can see that in cooling season full melting is taking place in all PCM layers from around 08:00 to 18:00). Interesting phenomenon takes place in night hours, when despite the fact that no solar radiation is available, high outside air temperatures doesn't allow PCM to solidify in any of layers $(\beta>0.0)$. This is 
important observation due to necessity of modelling mushy state in calculations aimed on assessing applicability and economic legitimacy of such solution. Results for cooling season with Polish weather data prove that proper modelling of mushy state is very important also in periods when full solidifying does not take place.

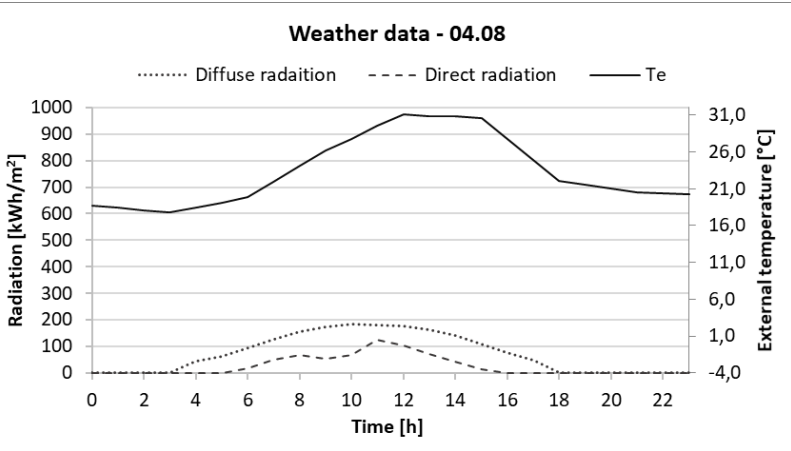

Figure 12. Weather data from typical meteorological year for $4^{\text {th }}$ of August.

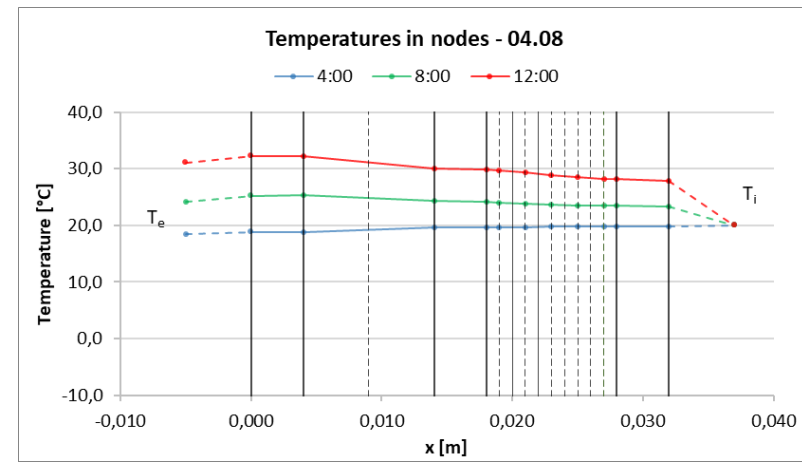

Figure 13. Temperatures in nodes of CVM model in exemplary hours before noon for $4^{\text {th }}$ of August.

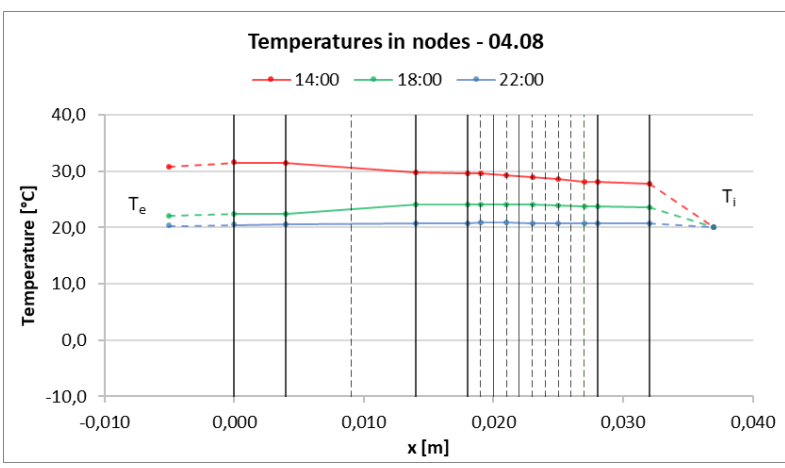

Figure 14. Temperatures in nodes of CVM model in exemplary hours after noon for $4^{\text {th }}$ of August.

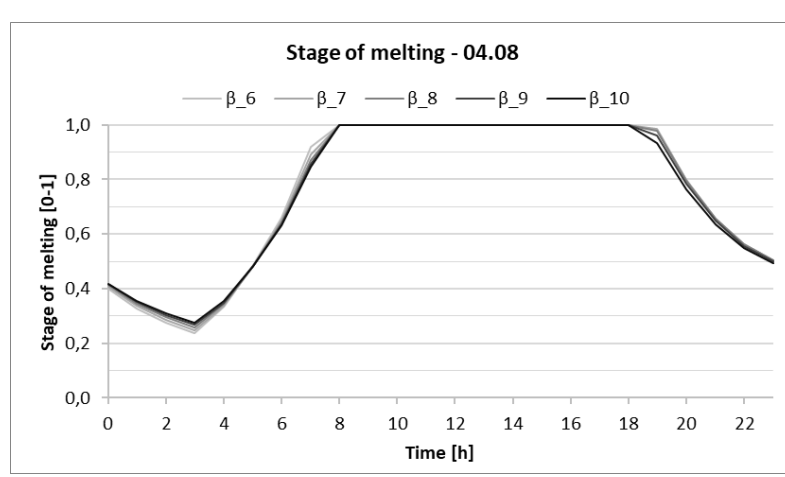

Figure 15. Stage of melting in layers 6-10 (nodes representing PCM layers) for each hour of the day ( $4^{\text {th }}$ of August).

\section{Conclusion}

In this study a mathematical model is proposed and used to simulate the thermal processes with latent heat storage in a case of triple glass windows filled with PCM. Control Volume Method which bases on integral formulation of extensive quantity conservation law was applied to heat transfer problem. For short wave radiation distribution within the glazing structure the Net Radiation Balancing Method was used. The initial results show the effect of detailed optical modelling of PCM layer (divided on the parts being in a different physical states) on temperature distribution in the whole glazing component.

\section{Acknowledgement}

This work was funded in a framework of ERANet-LAC $2^{\text {nd }}$ Joint Call on Research and Innovation by NCBiR as part of the project entitled: Solar hybrid translucent component for thermal energy storage in buildings (acronym: SOLTREN). 


\section{References}

Al-Saadi, Saleh Nasser, and Zhiqiang Zhai. 2013. "Modeling Phase Change Materials Embedded in Building Enclosure: A Review." Renewable and Sustainable Energy Reviews 21. Elsevier: 659673. doi:10.1016/j.rser.2013.01.024.

Alexiades, V., and A.D. Solomon. 1993. Mathematical Modeling of Melting and Freezing Processes. Journal of Fluid Mechanics. doi:10.1017/S0022112093213593.

Duffie, John A, and William A Beckman. 2001. Solar Engineering of Thermal Processes, 1991. Intersciences Publication, USA.

Goia, Francesco, Marco Perino, and Matthias Haase. 2012. "A Numerical Model to Evaluate the Thermal Behaviour of PCM Glazing System Configurations." Energy and Buildings 54. Elsevier B.V.: 141-153. doi:10.1016/j.enbuild.2012.07.036.

Goia, Francesco, Marco Perino, and Valentina Serra. 2014. "Experimental Analysis of the Energy Performance of a Full-Scale PCM Glazing Prototype." Solar Energy 100 (February). Pergamon: 217-233. doi:10.1016/j.solener.2013.12.002.

Heim, Dariusz, and Anna Wieprzkowicz. 2016. "Positioning of an Isothermal Heat Storage Layer in a Building Wall Exposed to the External Environment." Journal of Building Performance Simulation $\quad 9 \quad$ (5): $\quad$ 542-554. doi:10.1080/19401493.2015.1126649.

Lachheb, Mohamed, Zohir Younsi, Hassane Naji, Mustapha Karkri, and Sassi Ben Nasrallah. 2017. "Thermal Behavior of a Hybrid PCM/Plaster: A Numerical and Experimental Investigation." Applied Thermal Engineering 111. Elsevier Ltd: 49-59. doi:10.1016/j.applthermaleng.2016.09.083.

Li, Shuhong, Kecheng Zhong, Yingying Zhou, and Xiaosong Zhang. 2014. "Comparative Study on the Dynamic Heat Transfer Characteristics of PCM-Filled Glass Window and Hollow Glass Window." Energy and Buildings 85. Elsevier B.V.: 483-492. doi:10.1016/j.enbuild.2014.09.054.

Liu, Changyu, Yangyang Wu, Dong Li, Tengfei Ma, Ahmed Kadhim Hussein, and Yingming Zhou. 2018. "Investigation of Thermal and Optical Performance of a Phase Change Material-filled
Double-Glazing Unit." Journal of Building $\begin{array}{lll}\text { Physics } & 42 & \text { (2): }\end{array}$ doi:10.1177/1744259117708734.

Liu, Changyu, Yangyang Wu, Dong Li, Tengfei Ma, and Xiaoyan Liu. 2017. "Investigations on Thermal and Optical Performances of a Glazing Roof with PCM Layer." International Journal of Energy Research $41 \quad$ (14): 2138-2148. doi:10.1002/er.3775.

Olivieri, Lorenzo, José A. Tenorio, David Revuelta, Lidia Navarro, and Luisa F. Cabeza. 2018. "Developing a PCM-Enhanced Mortar for Thermally Active Precast Walls." Construction and Building Materials 181 (August). Elsevier: 638-649. doi:10.1016/j.conbuildmat.2018.06.013.

Rao, V. Venkateswara, R. Parameshwaran, and V. Vinayaka Ram. 2018. "PCM-Mortar Based Construction Materials for Energy Efficient Buildings: A Review on Research Trends." Energy and Buildings 158. Elsevier B.V.: 95-122. doi:10.1016/j.enbuild.2017.09.098.

Robert Siegel. 1999. "Thermal Radiation Heat Transfer." Journal of Physics D: Applied Physics. doi:10.1002/apj.5500020220.

Silva, Tiago, Romeu Vicente, and Fernanda Rodrigues. 2016. "Literature Review on the Use of Phase Change Materials in Glazing and Shading Solutions." Renewable and Sustainable Energy Reviews.

Pergamon. doi:10.1016/j.rser.2015.07.201.

Vicente, Romeu, and Tiago Silva. 2014. "Brick Masonry Walls with PCM Macrocapsules: An Experimental Approach." Applied Thermal Engineering 67 (12). Pergamon: 24-34. doi:10.1016/j.applthermaleng.2014.02.069.

Wang, Xu, Hang Yu, Lu Li, and Mei Zhao. 2016. "Research on Temperature Dependent Effective Thermal Conductivity of Composite-Phase Change Materials (PCMs) Wall Based on Steady-State Method in a Thermal Chamber." Energy and Buildings. doi:10.1016/j.enbuild.2016.05.058.

Weng, Ying Che, Hung Pin Cho, Chih Chung Chang, and Sih Li Chen. 2011. "Heat Pipe with PCM for Electronic Cooling." Applied Energy 88 (5). Elsevier Ltd: 1825-1833. doi:10.1016/j.apenergy.2010.12.004. 